\title{
SYNTHESIS AND EVALUATION OF 5-(6-METHOXYNAPHTHALEN-2-YL)-1-ARYL-1- (4-(TRIFLUOROMETHYL)PHENYLAMINO)PENTAN-3-ONE AS POTENTIAL ANTIDIABETIC AGENTS
}

\author{
HAN HAI-YAN ${ }^{a}, Y A N J U-F A N G^{b}, X U J_{I N}^{a}, Y E F i^{b}, F A N L I^{a}, Z H O U$ GUANG-MING ${ }^{a}, Y A N G$ DA-CHENG ${ }^{a *}$ \\ a School of Chemistry and Chemical Engineering, Southwest University, Chongqing 400715, China \\ ${ }^{b}$ Drug Screening Center, Chengdu Di Ao Pharmaceutical Group Co. Ltd, Chengdu 610041, China
}

(Received: May 2, 2011 - Accepted: October 11, 2011)

\begin{abstract}
We wish to report a set of seventeen $\beta$-amino ketones bearing nabumetone and trifluoro- methylaniline(TFMA) moieties. Synthesized via direct Mannich reaction in a solution of ethanol- chloroform catalyzed by concentrated hydrochloric acid, the chemical structures of these compounds were characterized by IR, ${ }^{1} \mathrm{H}$ NMR, ${ }^{13} \mathrm{C}$ NMR, ESI MS and HR MS. Studies on their antidiabetic activities revealed that all title compounds possessed moderate $\alpha$-glucosidase inhibitory activities and protein tyrosine phosphatase 1B (PTP 1B) inhibitory activities. Among them, a few compounds also exhibit considerable peroxisome proliferatoractivated receptor response element (PPRE) agonist activity, in particular the relative PPRE agonist activity of compounds $1 \mathrm{r}$ and $1 \mathrm{l}$ reached 54.02\% and 57.60\%, respectively. These results represent significant examples of new molecular type for antidiabetic agents that merit further evaluation.
\end{abstract}

Keywords: Diabetes Mellitus, PPRE, $\alpha$-Glucosidase, PTP 1B, $\beta$-Amino ketones, Mannich base

\section{INTRODUCTION}

Diabetes mellitus is a common chronic metabolic disease characterized by hyperglycemia and a host of metabolic imbalances. Clinically diabetes is generally classified into two categories: Type 1 diabetes mellitus (T1DM) and Type 2 diabetes mellitus (T2DM), with the latter accounts for approximately 95\% cases. The World Health Organization (WHO) estimates that more than 180 million people worldwide currently suffer from diabetes, which is likely to double by $2030^{1}$. Although several mainstream drugs of oral therapeutic agents for T2DM have been marketed, such as insulin sensitizer (TZDs ${ }^{2}$ or "glitazones"3), insulinotropic secretion medicine (sulfonylureas4), glycosidase inhibitors $^{5}$ and DPP-4 inhibitors (vildagliptin ${ }^{6}$, sitagliptin ${ }^{7}$ and saxagliptin ${ }^{8}$ ), these clinical drugs usually exert a number of side effects with degenerative complications including weight gain, congestive heart failure, edema, hepatotoxicity, indigestion', and so on. Therefore, the development of new antidiabetic agents with higher efficiency and lower toxicity is highly desirable.

The Mannich reaction is a critical step in the synthesis of numerous pharmaceuticals, natural products and versatile synthetic intermediates ${ }^{10}$ Notably, it is a classical method for the preparation of $\beta$-amino ketones. Efforts have been devoted to the pharmaceutical activities of $\beta$-amino ketones for anticancer $^{11}$, antibacterial ${ }^{12}$, anti-inflammatory ${ }^{13}$ and antiandrogen ${ }^{14}$, but little study has been directed to investigate the antidiabetic activity of $\beta$-amino ketones.

In an endeavor to search for novel $\beta$-amino ketones with antidiabetic activity, the selection of component of Mannich reaction is crucial. As reported, nabumetone is frequently prescribed as non-acidic, non-steroidal, anti-inflammatory drug (NSAID) for symptomatic treatment of rheumatic and inflammatory conditions ${ }^{15,16}$. Moreover, 4-trifluoromethylaniline (TFMA) is not only an important fine organic fluorine-containing material, it has also been widely used in pesticide, medicine, dyes and fluorinated polymers ${ }^{17-19}$. Based on these considerations and our previous work on $\beta$-amino ketone ${ }^{20}$, we assumed that introduction of TFMA and nabumetone into $\beta$-amino ketones would lead to new molecules with novel bioactivities. By exploring the experimental conditions systematically, we achieved the Mannich reaction of nabumetone, TFMA and some aromatic aldehydes, thus for the first time prepared seventeen $\beta$-amino ketones incorporating TFMA unit with the yield in the range of $61 \%$ $97 \%$ (Scheme 1).

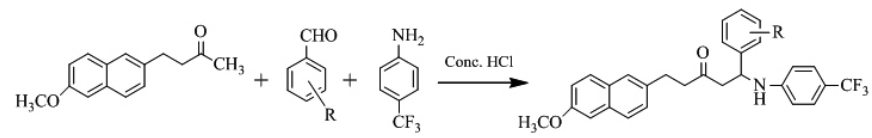

1a 1r: $\mathrm{R}=$ (a) 4-NO; (b) 3-NO; (c) 2,4-diCl; (d) 3,4-diCl; (e) 3-F; (f) 4-Cl; (g) 3-Cl; (i) 3-OH; (j) 3-OCH $;$; (k) $\mathrm{H}$; (I) 4-Br; (m) 3- $\mathrm{CH}_{3}$;

(n) $4-\mathrm{CH}_{3} ;$ (o) $4-\mathrm{OCH}_{3} ;$ (p) $4-\mathrm{OC}_{4} \mathrm{H}_{9} ;$ (q) $3,4-\mathrm{OCH}_{2} \mathrm{O} ;$ (r) $4-\mathrm{OH}$

Scheme 1 Synthesis of Mannich bases containing TFMA

\section{RESULTS AND DISCUSSION}

\subsection{Chemistry}

It is commonly understood that $\beta$-amino ketones can be synthesized by such methods as direct Mannich reaction involving aldehydes, ketones and amines; Michael addition of aromatic amines and $\alpha, \beta$-unsaturated ketones ${ }^{21}$; exchange of amine $\mathrm{e}^{22}$ or ketone $\mathrm{e}^{23}$; or condensation of Schiff base with aromatic ketones $^{24}$. Among them Mannich reaction is the most popular in the preparation of $\beta$-amino ketones because of higher "atom economy" and its "green" nature. The Mannich reaction relies on two as well as three component system, but the preferable route is the use of a one-pot three component setup rather than a two-step method $^{25}$. We adopted the one-pot protocol by first reacting aldehyde with amine to form Schiff base, followed by adding ketone to yield the title molecules. This protocol brings on board a number of advantages of convenient handling, easy judgment of completion and higher yields (Table 3 ). The chemical structures of the title compounds were characterized by IR, MS, HR MS, ${ }^{1} \mathrm{H}$ NMR and ${ }^{13} \mathrm{C}$ NMR.

\subsection{Key factors affecting the Mannich reaction}

The Mannich reaction of nabumetone, TFMA and all selected aldehydes proceeded readily in an ethanol-chloroform mixture solution, catalyzed by concentrated hydrochloric acid at $13-32^{\circ} \mathrm{C}$. Variation of reaction temperature within the above range does not have significant influence on the reaction yield.

Various catalysts, such as Lewis $\operatorname{acid}^{26}$, Brönsted $\operatorname{acid}^{27}$, Lewis base ${ }^{28}$, Lanthanide ${ }^{29}$, transition metal ${ }^{30}$ have been used for the synthesis of $\beta$-amino ketones. It was however still desirable to develop more cost- effective catalyst of higher performances. A number of catalysts were tested in the model reaction (Table 1) of nabumetone, TFMA and benzaldehyde. These include hydrochloric acid, phosphoric acid, acetic acid, ferric chloride, aluminum chloride and iodine. The concentrated hydrochloric acid was found to be the best as indicated by the experimental results.

Table 1: Influence of catalyst on the yield of the model reaction.

\begin{tabular}{|c|c|c|c|}
\hline Compd. & Catalyst & Time/h & Yield/\% \\
\hline 11 & Conc.HCl & 43 & $>80^{*}$ \\
\hline 11 & $\mathrm{H}_{3} \mathrm{PO}_{4}$ & 43 & $<10^{*}$ \\
\hline 11 & HOAc & 44 & $<30^{*}$ \\
\hline 11 & $\mathrm{FeCl}_{3}$ & 45 & $<10^{*}$ \\
\hline 11 & $\mathrm{AlCl}_{3}$ & 45 & $<10^{*}$ \\
\hline 11 & $\mathrm{I}_{2}$ & 45 & $<40 *$ \\
\hline 11 & HCl-EtOAc & 56 & 41.7 \\
\hline 11 & Conc.HCl & 24 & 79.6 \\
\hline
\end{tabular}

\# All reactions were carried out at $26^{\circ} \mathrm{C}$ in EtOH; * the yield was estimated by TLC. 
Furthermore, the substituent(s) on the benzaldehyde ring of aromatic aldehydes has/have great impact on the yield. Aromatic aldehyde bearing either strong electron-withdrawing or electron-donating substituent on the benzene ring lead to lower yield, following the order 1a $\left(4-\mathrm{NO}_{2}\right)<\mathbf{1 n}$ (4$\left.\mathrm{CH}_{3}\right), \mathbf{1 b}\left(3-\mathrm{NO}_{2}\right)<\mathbf{1 m}\left(3-\mathrm{CH}_{3}\right), \mathbf{1 q}\left(3,4-\mathrm{OCH}_{2} \mathrm{O}\right)<\mathbf{1 0}\left(4-\mathrm{OCH}_{3}\right)$. 3-Hydoxyand 4-hydroxybenzaldehyde could deliver to their corresponding Mannich bases with more than $60 \%$ yield, but 2-chlorobenzaldehyde, probably its steric hindrance, could not. The yield was also found solvent dependent. A few solvents, such as methanol, acetone, ethanol, benzene, and the ethanolchloroform mixture were explored in above model reaction (Table 2). The results indicated that the mixture of ethanol and chloroform was the most suitable solvent, probably due to a improved solubility of nabumetone in chloroform is much more than in other solvents. Thus, the optimum conditions were established as follows: the catalyst was concentrated hydrochloric acid, in an ethanol-chloroform mixture solution at a temperature range of $13-31^{\circ} \mathrm{C}$.

Table 2: Influence of solvents on the yield of the model reactio

\begin{tabular}{|c|c|c|c|c|}
\hline Entry & Compd. & Solvent & Time/h & Yield/\% \\
\hline 1 & $\mathbf{1 1}$ & $\mathrm{Me}_{2} \mathrm{CO}$ & 42 & $<30^{*}$ \\
\hline 2 & $\mathbf{1 1}$ & $\mathrm{EtOH}$ & 43 & Not detected \\
\hline 3 & $\mathbf{1 1}$ & $\mathrm{MeOH}$ & 44 & $<50^{*}$ \\
\hline 4 & $\mathbf{1 1}$ & $\mathrm{C}_{6} \mathrm{H}_{6}$ & 50 & Not detected \\
\hline 5 & $\mathbf{1 1}$ & $\mathrm{EtOH}-\mathrm{CHCl}_{3}$ & 24 & $>75^{*}$ \\
\hline
\end{tabular}

\# All reactions were carried out at $26{ }^{\circ} \mathrm{C}$ with catalyst concentrated hydrochloric acid; * the yield was estimated by TLC.

To check the scope of the optimized conditions and obtain title compounds, some other aromatic benzaldehydes were exploited. These results were shown in Table 3.

Table 3: Experimental conditions and results.

\begin{tabular}{|c|c|c|c|c|c|}
\hline Compd. & $\mathbf{R}$ & $\begin{array}{c}\text { Temp. } \\
/{ }^{\circ} \mathbf{C}\end{array}$ & $\begin{array}{c}\text { Time } \\
\mathbf{/ h}\end{array}$ & $\mathbf{p H}$ & $\begin{array}{c}\text { Yield } \\
/ \%\end{array}$ \\
\hline $\mathbf{1 a}$ & $4-\mathrm{NO}_{2}$ & 28 & 27 & $4-5$ & 75 \\
\hline $\mathbf{1 b}$ & $3-\mathrm{NO}_{2}$ & 28 & 31 & $3-4$ & 76 \\
\hline $\mathbf{1 c}$ & $2,4-\mathrm{diCl}$ & 20 & 47 & $3-4$ & 77 \\
\hline $\mathbf{1 d}$ & $3,4-\mathrm{diCl}$ & 30 & 29 & $4-5$ & 89 \\
\hline $\mathbf{1 e}$ & $3-\mathrm{F}$ & 13 & 23 & $4-5$ & 80 \\
\hline $\mathbf{1 f}$ & $4-\mathrm{Cl}$ & 31 & 22 & $4-5$ & 76 \\
\hline $\mathbf{1 g}$ & $3-\mathrm{Cl}$ & 29 & 25 & $4-5$ & 68 \\
\hline $\mathbf{1 i}$ & $3-\mathrm{OH}$ & 13 & 25 & $3-4$ & 61 \\
\hline $\mathbf{1 j}$ & $3-\mathrm{OCH}_{3}$ & 13 & 25 & $4-5$ & 76 \\
\hline $\mathbf{1 k}$ & $4-\mathrm{Br}$ & 25 & 24 & $4-5$ & 89 \\
\hline $\mathbf{1 l}$ & $\mathrm{H}$ & 31 & 25 & $4-5$ & 79 \\
\hline $\mathbf{1 m}$ & $3-\mathrm{CH}_{3}$ & 31 & 23 & $4-5$ & 89 \\
\hline $\mathbf{1 n}$ & $4-\mathrm{CH}_{3}$ & 20 & 26 & $4-5$ & 95 \\
\hline $\mathbf{1 0}$ & $4-\mathrm{OCH}_{3}$ & 32 & 28 & $3-4$ & 87 \\
\hline $\mathbf{1 p}$ & $4-\mathrm{OC}_{4} \mathrm{H}_{9}$ & 25 & 22 & $4-5$ & 97 \\
\hline $\mathbf{1 q}$ & $3,4-\mathrm{OCH}_{2} \mathrm{O}$ & 30 & 28 & $4-5$ & 75 \\
\hline $\mathbf{1 r}$ & $4-\mathrm{OH}$ & 20 & 25 & $3-4$ & 88 \\
\hline
\end{tabular}

*All reactants were used at amount of $2 \mathrm{mmol}$.

\subsection{Biological activity}

At nmol concentration levels, the title compounds were evaluated in vitro for PPRE agonist activity, $\alpha$-glucosidase inhibitory activity and part of them were also tested for PTP 1B inhibitory activity (Table 4). The screened compounds showed $\alpha$-glucosidase comparable to PTP 1B inhibitory activity, while the relative PPRE agonist activity of compound $\mathbf{1 r}$ and $\mathbf{1 l}$ reached moderate levels at $54.02 \%$ and $57.60 \%$, respectively. The trends of above three kinds of bioactivities were shown in Figure 1.
Table 4: Biological activities of the title compounds*.

\begin{tabular}{|c|c|c|c|c|c|}
\hline $\begin{array}{c}\text { Com- } \\
\text { pd. }\end{array}$ & $\mathrm{R}$ & $\begin{array}{c}\text { Conc. } \\
n m o l \cdot m L^{-1}\end{array}$ & $\begin{array}{c}\text { PPRE } \\
\text { agonist } \\
\text { activity } \\
/ \%\end{array}$ & $\begin{array}{c}\text { PTP 1B } \\
\text { inhibitory } \\
\text { activity } \\
/ \%\end{array}$ & $\begin{array}{c}\alpha- \\
\text { Glucosidase } \\
\text { inhibitory } \\
\text { activity } / \%\end{array}$ \\
\hline $\mathbf{1 a}$ & $4-\mathrm{NO}_{2}$ & 19.2 & -16.53 & -2.37 & 6.88 \\
\hline $\mathbf{1 b}$ & $3-\mathrm{NO}_{2}$ & 19.2 & 34.0 & -11.79 & 1.33 \\
\hline $\mathbf{1 c}$ & $2,4-\mathrm{diCl}$ & 18.3 & 22.92 & - & 3.17 \\
\hline $\mathbf{1 d}$ & $3,4-\mathrm{diCl}$ & 18.3 & 35.80 & -3.23 & 13.13 \\
\hline $\mathbf{1} \mathbf{e}$ & $3-\mathrm{F}$ & 20.2 & 32.57 & - & -1.52 \\
\hline $\mathbf{1 f}$ & $4-\mathrm{Cl}$ & 19.6 & 22.70 & -0.27 & 7.19 \\
\hline $\mathbf{1 g}$ & $3-\mathrm{Cl}$ & 19.6 & 29.70 & -7.94 & 6.38 \\
\hline $\mathbf{1 i}$ & $3-\mathrm{OH}$ & 20.3 & 9.58 & - & -0.75 \\
\hline $\mathbf{1 j}$ & $3-\mathrm{OCH}_{3}$ & 19.7 & -6.26 & - & -0.61 \\
\hline $\mathbf{1 k}$ & $4-\mathrm{Br}$ & 18.1 & 4.58 & - & 1.42 \\
\hline $\mathbf{1 I}$ & $\mathrm{H}$ & 21.0 & $\mathbf{5 7 . 6 0}$ & -3.47 & 9.09 \\
\hline $\mathbf{1 m}$ & $3-\mathrm{CH}_{3}$ & 20.4 & -0.60 & 1.66 & 1.80 \\
\hline $\mathbf{1 n}$ & $4-\mathrm{CH}_{3}$ & 20.4 & 17.91 & - & 9.97 \\
\hline $\mathbf{1 0}$ & $4-\mathrm{OCH}_{3}$ & 19.7 & 31.11 & -3.91 & 7.43 \\
\hline $\mathbf{1 p}$ & $4-\mathrm{OC}_{4} \mathrm{H}_{9}$ & 18.2 & 13.75 & - & 0.36 \\
\hline $\mathbf{1 q}$ & $3,4-\mathrm{OCH}_{2} \mathrm{O}$ & 19.2 & 15.00 & -3.20 & 5.96 \\
\hline $\mathbf{1 r}$ & $4-\mathrm{OH}$ & 20.3 & $\mathbf{5 4 . 0 2}$ & - & 0.83 \\
\hline
\end{tabular}

*PPRE agonist activation of Rosiglitazone $\left(28.0 \mathrm{nmol} \cdot \mathrm{mL}^{-I}\right)$ is $100 \%$; PTP1B inhibitory activity of Soduim Orthovanadate $\left(54.4 \mathrm{nmol} \cdot \mathrm{mL}^{-1}\right)$ is $93.31 \%$; $\alpha$-Glucosidase inhibitory activity of Acarbose $\left(154.9 \mathrm{nmol} \cdot \mathrm{mL}^{-1}\right)$ is $74.12 \%$.

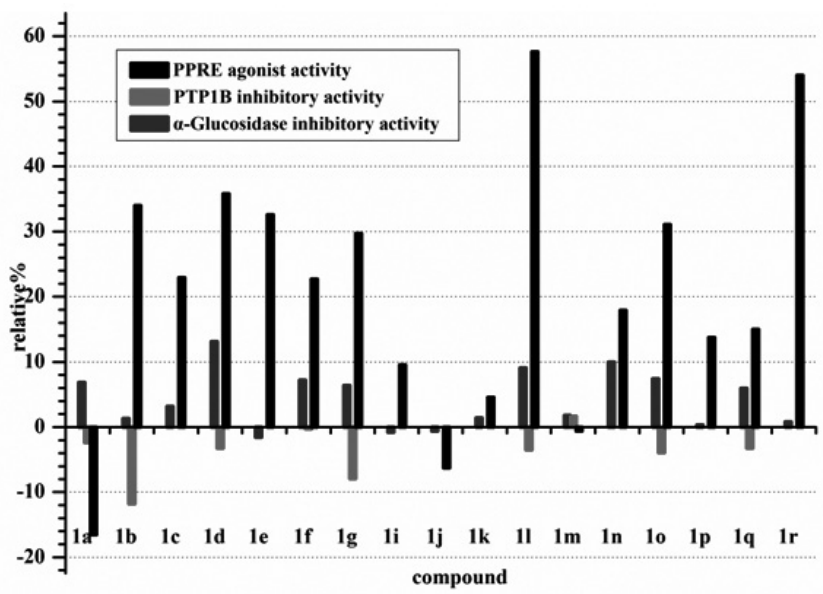

Figure 1 Trend graph of biological activities of title compounds.

As shown in Table 4, the effect of substitution of aromatic aldehydes on PPRE agonist depends on the nature and substituted position. As for chlorosubstituted aromatic aldehydes, the activity of dichloro-substituted compound is stronger than that of monochloro-substituted compound, such as $\mathbf{1 c}(2,4-\mathrm{diCl})$ $>\mathbf{1 f}(4-\mathrm{Cl}) ; \mathbf{1 d}(3,4-\mathrm{diCl})>\mathbf{1 g}(3-\mathrm{Cl})$. For those title compounds originated from $m e t a$-substituted aromatic aldehydes, their agonist activity were exhibited as follows: $\mathbf{1 b}\left(3-\mathrm{NO}_{2}\right)>\mathbf{1 e}(3-\mathrm{F})>\mathbf{1 g}(3-\mathrm{Cl})>\mathbf{1 i}(3-\mathrm{OH})>\mathbf{1 j}\left(3-\mathrm{OCH}_{3}\right)>\mathbf{1 m}$ $\left(3-\mathrm{CH}_{3}\right)$ (Figure 2). For the aromatic aldehydes having para-substituted group, the activities of corresponding compounds were: $\mathbf{1 a}\left(4-\mathrm{NO}_{2}\right)<\mathbf{1 k}(4-\mathrm{Br})<\mathbf{1 p}$ $\left(4-\mathrm{C}_{4} \mathrm{H}_{9} \mathrm{O}\right)<\mathbf{1 n}\left(4-\mathrm{CH}_{3}\right)<\mathbf{1 f}(4-\mathrm{Cl})<\mathbf{1 o}\left(4-\mathrm{OCH}_{3}\right)<\mathbf{1 r}(4-\mathrm{OH})$ (Figure 3). As aromatic aldehydes having electron-donating substituent, the activities of para-substituted aromatic aldehydes were stronger than that in the case of a meta position, such as $\mathbf{1 r}(4-\mathrm{OH})>\mathbf{1 i}(3-\mathrm{OH}), \mathbf{1 0}\left(4-\mathrm{OCH}_{3}\right)>\mathbf{1 j}\left(3-\mathrm{OCH}_{3}\right)$, 1n $\left(4-\mathrm{CH}_{3}\right)>\mathbf{1 m}\left(3-\mathrm{CH}_{3}\right)$. In contrast, as aromatic aldehydes having electronwithdrawing substituent, the activities of meta-substituted aromatic aldehydes were stronger than that of the para-substituted (e.g., $\mathbf{1 b}\left(3-\mathrm{NO}_{2}\right)>\mathbf{1 a}\left(4-\mathrm{NO}_{2}\right)$, $\lg (3-\mathrm{Cl})>1 \mathbf{f}(4-\mathrm{Cl}))$. 


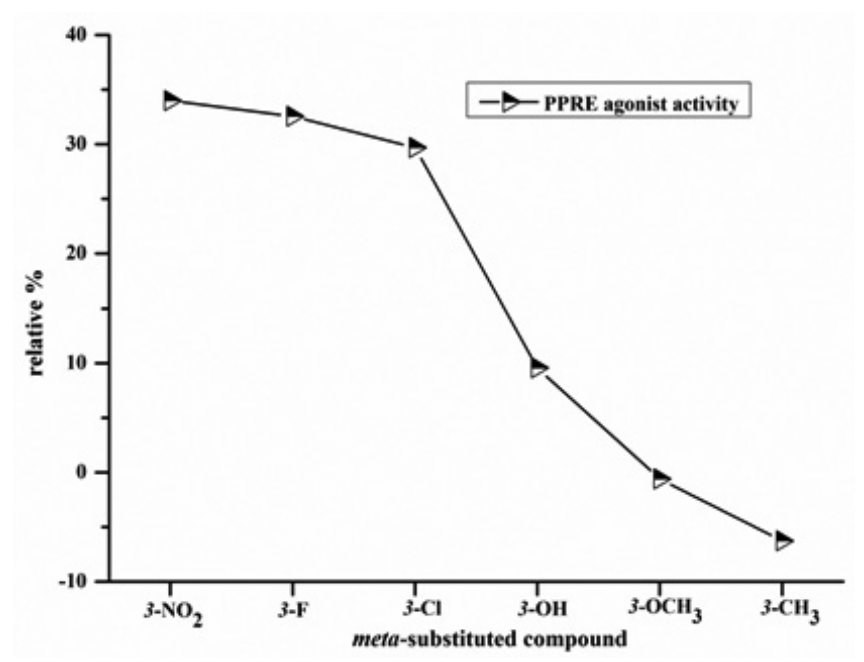

Figure 2: Trend graph of PPRE agonist activity of meta-substituted compounds.

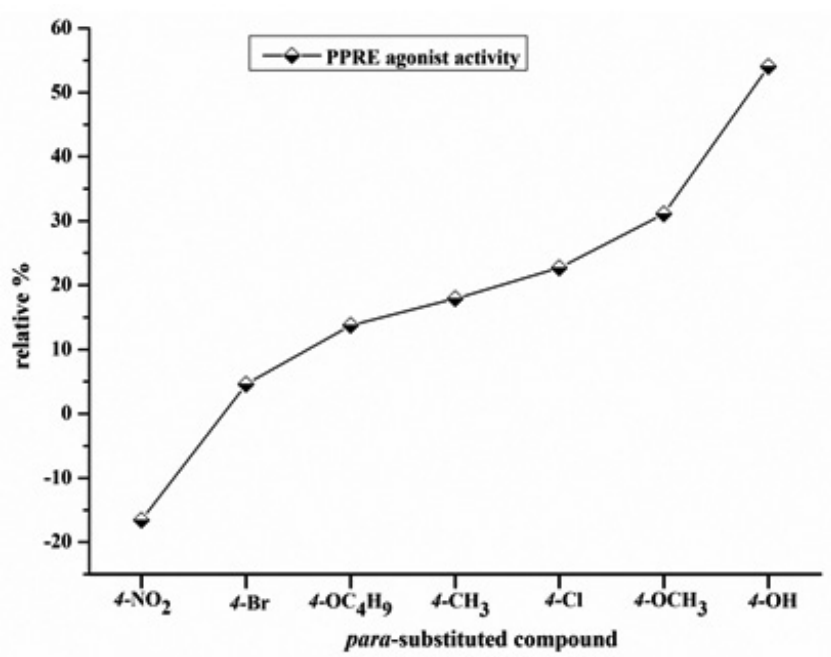

Figure 3: Trend graph of PPRE agonist activity of para-substituted compounds.

\section{CONCLUSION}

$\beta$-amino ketones containing a nabumetone and TFMA unit could be synthesized through direct Mannich reaction under optimized synthetic conditions, and compounds $\mathbf{1 r}$ and $\mathbf{1 l}$ possessed moderate PPRE agonist activity. These results provided the foundation for further investigation.

\section{EXPERIMENTAL}

Melting points were determined with an electrothermal X-6 apparatus and were not calibrated. ${ }^{1} \mathrm{H}-\mathrm{NMR}$ spectra were recorded in DMSO- $d_{6}$ solution on a Bruker AV-300 spectrometer at $300 \mathrm{MHz}$ with chemical shifts reported in ppm downfield relative to TMS as the internal standard. ESI-MS were obtained on an Agilent 1946B instrument. HR-MS values were measured on a Daltonics Data Analysis 3.2 mass spectrometer. Samples were prepared in $\mathrm{KBr}$ disks. $\alpha$-Glucosidase (Sigma G-0660) was purchased from Sigma-Aldrich Co. Ltd. Glucose assay kit was purchased from Nanjing Jiancheng Biotechnology Co. Ltd. Aromatic aldehyde, nabumetone and trifluoromethylaniline were of chemical grade. All other chemicals used were of analytical grade.

4.1 General procedure

To the solution of TFMA ( $2 \mathrm{mmol})$ in ethanol $(5 \mathrm{~mL})$ was added aromatic aldehyde $(2 \mathrm{mmol}$ ) with constant stirring at controlled temperature for about 20 $\mathrm{min}$. After formation of Schiff base as monitored by TLC, nabumetone ( $2 \mathrm{mmol})$ in chloroform solution was added with constant stirring. The reaction mixture was then adjusted to the selected $\mathrm{pH}$ 3-4 with concentrated hydrochloric acid. The mixture was stirred vigorously and the progress was monitored by TLC. After completion, the mixture was kept in the refrigerator $\left(4^{\circ} \mathrm{C}\right)$ overnight. The solids were subsequently collected by filtration with suction on a sintered glass funnel. The filter cake was washed consecutively with water $(2 \times 1.5 \mathrm{~mL})$ and absolute ethanol $(2 \times 1.5 \mathrm{~mL})$, and then dried to afford the corresponding crude products. The crude products were recrystallized in toluene or a mixture of ethyl acetate and cyclohexane (1:2 1:6, ratio of volume), dried over $\mathrm{P}_{2} \mathrm{O}_{5}$ in vacuum to obtain the pure product. The results were in Table 3 .

\subsection{Inspection and Test of PPRE agonist activity}

HepG2 cells was cultured in low glucose DMEM supplement with $100 \mathrm{U}$ - $\mathrm{mL}^{-1}$ streptomycin and penicillin. One day before transfection, the cells were plated in 96-well plates with $1.5 \times 10^{4}$ cells per well. When the cells grew at confluence of $70 \%$, plasmid pPPRE-Luc with firefly luciferase reporter gene and the control plasmid phRL-TK with renilla luciferase reporter gene were transfected into the cells. $24 \mathrm{~h}$ after the transfection, the medium was replaced with fresh medium containing either different samples, Rosiglitazone (positive control) or without sample (negative control). The cells without transfection were used as blank control. After a further $24 \mathrm{~h}$ incubation, the expression of luciferases were measured with Dual-Luciferase Reporter Gene Assay Kit (Promega). The times the samples activated (T\%) were calculated as the following equation: $\mathrm{T} \%=\left[\left(\mathrm{L} 1_{\text {Sample }}-\mathrm{L} 1_{\text {Blank }}\right) /\left(\mathrm{L} 1_{\text {Negative }}-\mathrm{L} 1_{\text {Blank }}\right)\right] /\left[\left(\mathrm{L} 2_{\mathrm{S}}\right.\right.$ $\left.\left.-\mathrm{L} 2_{\text {Blank }}\right) /\left(\mathrm{L} 2_{\text {Negative }}-\mathrm{L} 2_{\text {Blank }}\right)\right] \times 100 \%$. Here, $\mathrm{L} 1$ represents the values of firefly luciferase and $\mathrm{L} 2$ was the values of Renilla luciferase. The concentration of the samples were $10 \mu \mathrm{g} \cdot \mathrm{mL}^{-1}$.

\subsection{The determination of $\alpha$-glucosidase inhibitory activity}

$\alpha$-Glucosidase activity was determined in a $100 \mu \mathrm{L}$ reaction mixture containing optimal rat- $\alpha$-glucosidase (extracted from the small intestine of rat), $67 \mathrm{mmol} \cdot \mathrm{L}^{-1} \mathrm{pH} 6.8$ sodium phosphate buffer and different samples. Blank control (without enzyme or samples) or negative control (without sample) was set as the above. After incubation at $37^{\circ} \mathrm{C}$ for $10 \mathrm{~min}, 0.1 \mathrm{~mol} \cdot \mathrm{L}^{-1}$ maltose was added and incubated for another $10 \mathrm{~min}$ at room temperature. The reaction was stopped with $200 \mu \mathrm{L}$ of glucose testing reagents and the OD values at 490 $\mathrm{nm}$ measured. The inhibition rate was calculated according to the following

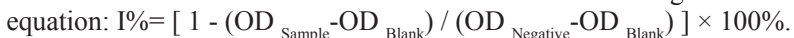

\subsection{Assay of PTP1B Activity}

Recombinant human GST-PTP1B (1-321 aa) was made by gene cloning, and expressed and purified from E. coli. . The enzyme activity was determined as described previously Takayuki Suzuki. The reaction was initiated by adding the enzyme into both the samples, $\mathrm{Na}_{3} \mathrm{VO}_{4}$ (positive control) or without sample (negative control) in the reaction buffer $\left(100 \mathrm{mmol} \cdot \mathrm{L}^{-1}\right.$ Sodium acetate, 15 $\mathrm{mmol} \cdot \mathrm{L}^{-1} \beta$-mercaptoethanol, $1 \mathrm{mmol} \cdot \mathrm{L}^{-1}$ EDTA, $0.1 \%$ Triton X-100, $\mathrm{pH} 6.0$ ) with a total volume of $200 \mu \mathrm{L}$. The blank control (without enzyme and samples) and negative control (without samples) were set. After incubation for $10 \mathrm{~min}$ for $37^{\circ} \mathrm{C}, 5 \mathrm{mmol} \cdot \mathrm{L}^{-1} p$-nitrophenyl phosphate was added and incubated for another $30 \mathrm{~min}$ at $37^{\circ} \mathrm{C}$. Then, the reaction was stoped with $1 \mathrm{~mol} \cdot \mathrm{L}^{-1} \mathrm{NaOH}$ and the OD values at $405 \mathrm{~nm}$ were measured. The inhibition rate (I\%) was calculated according to the following equation: $\mathrm{I} \%=\left[1-\left(\mathrm{OD}_{\mathrm{Sample}}-\mathrm{OD}_{\mathrm{Blank}}\right) /\right.$ $\left.\left(\mathrm{OD}_{\text {Negative }}-\mathrm{OD}_{\text {Blank }}\right)\right] \times 100 \%$. All the assays above were performed in duplicate and repeated twice.

\section{Supporting Information}

Target compounds were characterized by IR, ${ }^{1} \mathrm{H}$ NMR, ${ }^{13} \mathrm{C}$ NMR, MS and HRMS. Spectral and analytical data are as follow:

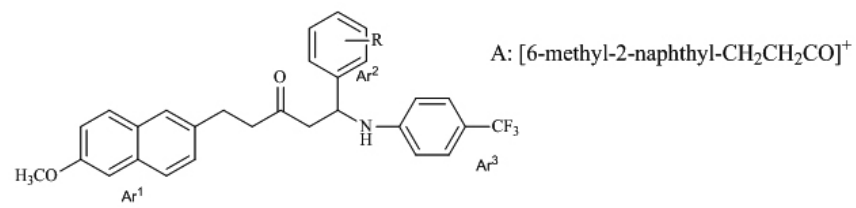

(1a) 5-(6-Methoxynaphthalen-2-yl)-1-(4-nitrophenyl)-1-(4(trifluoromethyl)phenylamino)pentan-3-one $(R=4-N O)$ m.p. $168-170^{\circ} \mathrm{C}^{\circ} \mathrm{IR}$ $(\mathrm{KBr}): v 3399\left(v_{\mathrm{NH}}\right), 1711\left(\mathrm{v}_{\mathrm{C}=\mathrm{O}}\right), 1615\left(\mathrm{v}_{\mathrm{C}=\mathrm{C}}\right), 1518,1336\left(\mathrm{n}_{\mathrm{NO} 2}\right) \mathrm{cm}^{-1} ;{ }^{1} \mathrm{H} \mathrm{NMR}$ (300 MHz, DMSO-d $\left.\mathrm{d}_{6}\right): \delta 2.69$ (dd, $\left.2 \mathrm{H}, J=7.9,17.6 \mathrm{~Hz},{ }^{*} \mathrm{CHCH}_{2}\right), 2.87(\mathrm{~d}, 2 \mathrm{H}$, $\left.J=6.1 \mathrm{~Hz}, \mathrm{CH}_{2}\right), 2.99\left(\mathrm{t}, 2 \mathrm{H}, J=7.1 \mathrm{~Hz}, \mathrm{CH}_{2}\right), 3.92\left(\mathrm{~s}, 3 \mathrm{H}, \mathrm{OCH}_{3}\right), 4.74-4.81$ $\left(\mathrm{m}, 1 \mathrm{H},{ }^{*} \mathrm{CH}\right), 6.42\left(\mathrm{~d}, 2 \mathrm{H}, J=8.4 \mathrm{~Hz}, \mathrm{Ar}^{3}-\mathrm{H}\right), 7.09\left(\mathrm{~d}, 1 \mathrm{H}, J=1.5 \mathrm{~Hz}, \mathrm{Ar}^{1}-\mathrm{H}\right)$, 7.10-7.18 (m, 2H, $\left.\mathrm{Ar}^{1}-\mathrm{H}\right), 7.29\left(\mathrm{~d}, 2 \mathrm{H}, J=8.6 \mathrm{~Hz}, \mathrm{Ar}^{3}-\mathrm{H}\right), 7.39$ (d, $2 \mathrm{H}, J=8.6$ $\left.\mathrm{Hz}, \mathrm{Ar}^{2}-\mathrm{H}\right), 7.45\left(\mathrm{~s}, 1 \mathrm{H}, \mathrm{Ar}^{1}-\mathrm{H}\right), 7.59\left(\mathrm{~d}, 2 \mathrm{H}, J=8.0 \mathrm{~Hz}, \mathrm{Ar}^{1}-\mathrm{H}\right), 8.06(\mathrm{~d}, 2 \mathrm{H}$, $\left.J=8.6 \mathrm{~Hz}, \mathrm{Ar}^{2}-\mathrm{H}\right) ;{ }^{13} \mathrm{C}$ NMR (75 MHz, DMSO-d $): \delta 29.8,45.3,50.4,53.2$, $55.4,105.8,113.2(2 \mathrm{C}), 118.9,119.2(2 \mathrm{C}), 121.2(2 \mathrm{C}), 125.4(2 \mathrm{C}), 127.5,127.8$, $128.2,128.5,129.0,129.1,130.0,132.8,133.2,144.3,146.7,148.9,157.6$, 
207.8; MS (m/z, \%): $523.2\left([\mathrm{M}+\mathrm{H}]^{+}, 100\right), 545.2\left([\mathrm{M}+\mathrm{Na}]^{+}, 9\right), 213.2(\mathrm{~A}, 16)$; HR MS: formula: $\mathrm{C}_{29} \mathrm{H}_{25} \mathrm{~F}_{3} \mathrm{~N}_{2} \mathrm{NaO}_{4}$, cald: 545.1659, found: 545.1648.

(1b) 5-(6-Methoxynaphthalen-2-yl)-1-(3-nitrophenyl)-1-(4(trifluoromethyl)phenylamino)pentan-3-one $\left(R=3-\mathrm{NO}_{2}\right)$ m.p. $145-147^{\circ} \mathrm{C} ; \mathrm{IR}$ $(\mathrm{KBr}): v 3345\left(\mathrm{v}_{\mathrm{NH}}\right), 1705\left(\mathrm{v}_{\mathrm{C}=\mathrm{O}}\right), 1613\left(\mathrm{v}_{\mathrm{C}=\mathrm{C}}\right), 1533,1326\left(\mathrm{n}_{\mathrm{NO} 2}\right) \mathrm{cm}^{-1} ;{ }^{1} \mathrm{H} \mathrm{NMR}$ $\left(300 \mathrm{MHz}, \mathrm{DMSO}-\mathrm{d}_{6}\right): \delta 2.79\left(\mathrm{t}, 2 \mathrm{H}, J=7.2 \mathrm{~Hz}, \mathrm{CH}_{2}\right), 2.93(\mathrm{~d}, 2 \mathrm{H}, J=6.0$ $\left.\mathrm{Hz}, \mathrm{CH}_{2}\right), 2.99$ (t, $\left.2 \mathrm{H}, J=7.1 \mathrm{~Hz}, \mathrm{CH}_{2}\right), 3.92\left(\mathrm{~s}, 3 \mathrm{H}, \mathrm{OCH}_{3}\right), 4.83-4.91(\mathrm{~m}, 1 \mathrm{H}$, $\left.{ }^{*} \mathrm{CH}\right), 6.43\left(\mathrm{~d}, 2 \mathrm{H}, J=8.5 \mathrm{~Hz}, \mathrm{Ar}^{3}-\mathrm{H}\right), 7.09\left(\mathrm{~s}, 1 \mathrm{H}, \mathrm{Ar}^{1}-\mathrm{H}\right), 7.13-7.15(\mathrm{~m}, 1 \mathrm{H}$, $\left.\mathrm{Ar}^{1}-\mathrm{H}\right), 7.18\left(\mathrm{~d}, 1 \mathrm{H}, J=8.2 \mathrm{~Hz}, \mathrm{Ar}^{1}-\mathrm{H}\right), 7.29$ (d, 2H, $\left.J=8.6 \mathrm{~Hz}, \mathrm{Ar}^{3}-\mathrm{H}\right), 7.35$ $\left(\mathrm{d}, 1 \mathrm{H}, J=4.9 \mathrm{~Hz}, \mathrm{Ar}^{2}-\mathrm{H}\right), 7.45(\mathrm{~s}, 1 \mathrm{H}, \mathrm{ArH}), 7.60\left(\mathrm{~d}, 2 \mathrm{H}, J=8.5 \mathrm{~Hz}, \mathrm{Ar}^{1}-\mathrm{H}\right)$, 7.79-7.82 (d, $\left.1 \mathrm{H}, J=5.4 \mathrm{~Hz}, \mathrm{Ar}^{2}-\mathrm{H}\right), 8.03\left(\mathrm{~d}, 1 \mathrm{H}, J=8.2 \mathrm{~Hz}, \mathrm{Ar}^{2}-\mathrm{H}\right), 8.14$ (s, $\left.1 \mathrm{H}, \mathrm{Ar}^{2}-\mathrm{H}\right) ;{ }^{13} \mathrm{C}$ NMR (75 MHz, DMSO-d $\left.{ }_{6}\right): \delta 29.6,45.0,49.9,53.3,55.4$, $105.7,113.0,113.2,119.1,119.4,121.2,122.8,126.5,126.7,127.2,127.3$, 127.6, 129.0, 130.0, 132.7, 133.3, 133.6, 135.4, 144.2, 148.7, 157.4, 207.6; MS $(\mathrm{m} / \mathrm{z}, \%): 523.2\left([\mathrm{M}+\mathrm{H}]^{+}, 100\right), 545.5\left([\mathrm{M}+\mathrm{Na}]^{+}, 23\right), 213.2(\mathrm{~A}, 11) ; \mathrm{HR}$ MS: formula: $\mathrm{C}_{29} \mathrm{H}_{25} \mathrm{~F}_{3} \mathrm{~N}_{2} \mathrm{NaO}_{4}$, cald: 545.1659 , found: 545.1640

(1c) 1-(2,4-Dichlorophenyl)-5-(6-methoxynaphthalen-2-yl)-1-(4(trifluoromethyl)phenylamin)pentan-3-one $(R=2,4-d i C l)$ m.p. $114-115^{\circ} \mathrm{C}^{\circ 1} \mathrm{H}$ NMR (300 MHz, DMSO-d $): \delta 2.76\left(\mathrm{dd}, 2 \mathrm{H}, J=4.5,16.4 \mathrm{~Hz},{ }^{*} \mathrm{CHCH}_{2}\right), 2.80-$ $2.88\left(\mathrm{~m}, 4 \mathrm{H}, \mathrm{CH}_{2} \mathrm{CH}_{2}\right), 3.02\left(\mathrm{dd}, 1 \mathrm{H}, J=9.3,16.4 \mathrm{~Hz},{ }^{*} \mathrm{CHCH}_{2}\right), 3.85(\mathrm{~s}, 3 \mathrm{H}$, $\left.\mathrm{OCH}_{3}\right), 4.87-4.92\left(\mathrm{~m}, 1 \mathrm{H},{ }^{*} \mathrm{CH}\right), 6.50\left(\mathrm{~d}, 2 \mathrm{H}, J=8.6 \mathrm{~Hz}, \mathrm{Ar}^{3}-\mathrm{H}\right), 7.08-7.11$ (m, $2 \mathrm{H}, \mathrm{Ar}^{1}-\mathrm{H}$ and $\left.\mathrm{Ar}^{2}-\mathrm{H}\right), 7.12\left(\mathrm{~d}, 1 \mathrm{H}, J=8.7 \mathrm{~Hz}, \mathrm{Ar}^{1}-\mathrm{H}\right), 7.20(\mathrm{~d}, 1 \mathrm{H}, J=$ $\left.8.5 \mathrm{~Hz}, \mathrm{Ar}^{1}-\mathrm{H}\right), 7.29-7.34\left(\mathrm{~m}, 3 \mathrm{H}, 1 \mathrm{Ar}^{2}-\mathrm{H}\right.$ and $\left.2 \mathrm{Ar}^{3}-\mathrm{H}\right), 7.45\left(\mathrm{~s}, 1 \mathrm{H}, \mathrm{Ar}^{1}-\mathrm{H}\right)$, 7.59-7.63 (m, 2H, Ar $\left.{ }^{1}-\mathrm{H}\right), 7.78$ (s, 1H, $\left.\mathrm{Ar}^{2}-\mathrm{H}\right) ;{ }^{13} \mathrm{C}$ NMR (75 MHz, DMSO-d $)$ : $\delta$ 29.6, 43.6, 44.9, 52.6, 55.2, 105.7, 112.6, 113.0, 118.5, 119.3, 125.8(2C), $126.5,126.7,126.9,127.1,127.8,128.3,129.0,129.5,131.0,131.7,133.2$, 133.3, 135.5, 142.3, 148.9, 157.6, 207.2; MS (m/z, \%): $546.1\left([\mathrm{M}+\mathrm{H}]^{+}, 100\right)$, $568.0\left([\mathrm{M}+\mathrm{Na}]^{+}, 40\right), 213.2$ (A, 37); HR MS: formula: $\mathrm{C}_{29} \mathrm{H}_{24} \mathrm{Cl}_{2} \mathrm{~F}_{3} \mathrm{~N} \mathrm{NaO}$, cald: 568.1028 , found: 568.1022 .

(1d) 1-(3,4-Dichlorophenyl)-5-(6-methoxynaphthalen-2-yl)-1-(4(trifluoromethyl)phenylamino)pentan-3- one $(R=3,4-d i C l)$ m.p. $160-162^{\circ} \mathrm{C}^{\circ}$ IR (KBr): v $3396\left(v_{\mathrm{NH}}\right), 1715\left(v_{\mathrm{C}=\mathrm{O}}\right), 1615\left(v_{\mathrm{C}=\mathrm{C}}\right) ;{ }^{1} \mathrm{H}$ NMR $(300 \mathrm{MHz}$, DMSO-d $): \delta 2.75\left(\mathrm{dd}, 2 \mathrm{H}, J=7.9,17.6 \mathrm{~Hz},{ }^{*} \mathrm{CHCH}_{2}\right), 2.85(\mathrm{~d}, 2 \mathrm{H}, J=6.2 \mathrm{~Hz}$, $\left.\mathrm{CH}_{2}\right), 2.98\left(\mathrm{t}, 2 \mathrm{H}, J=7.1 \mathrm{~Hz}, \mathrm{H}_{2}\right), 3.92\left(\mathrm{~s}, 3 \mathrm{H}, \mathrm{OCH}_{3}\right), 4.69-4.75\left(\mathrm{~m}, 1 \mathrm{H},{ }^{*} \mathrm{CH}\right)$, $6.43\left(\mathrm{~d}, 2 \mathrm{H}, J=8.6 \mathrm{~Hz}, \mathrm{Ar}^{3}-\mathrm{H}\right), 7.07-7.10\left(\mathrm{~m}, 2 \mathrm{H}, \mathrm{Ar}^{1}-\mathrm{H}\right.$ and $\left.\mathrm{Ar}^{2}-\mathrm{H}\right), 7.13(\mathrm{~d}$, $\left.1 \mathrm{H}, J=9.1 \mathrm{~Hz}, \mathrm{Ar}^{1}-\mathrm{H}\right), 7.19$ (d, $\left.1 \mathrm{H}, J=8.4 \mathrm{~Hz}, \mathrm{Ar}^{1}-\mathrm{H}\right), 7.28-7.33(\mathrm{~m}, 3 \mathrm{H}$, $2 \mathrm{Ar}^{3}-\mathrm{H}$ and $\left.1 \mathrm{Ar}^{2}-\mathrm{H}\right), 7.47\left(\mathrm{~s}, 1 \mathrm{H}, \mathrm{Ar}^{1}-\mathrm{H}\right), 7.62\left(\mathrm{~d}, 2 \mathrm{H}, J=8.6 \mathrm{~Hz}, \mathrm{Ar}^{1}-\mathrm{H}\right), 7.84$ (s, $\left.1 \mathrm{H}, \mathrm{Ar}^{2}-\mathrm{H}\right) ;{ }^{13} \mathrm{C}$ NMR (75 MHz, DMSO-d ${ }_{6}$ ): $\delta 29.6,45.2,50.0,53.2,55.4$, $105.9,113.0(2 \mathrm{C}), 119.1,119.9,125.7(2 \mathrm{C}), 126.5,126.6,126.7,127.2,127.4$, 128.3, 129.0, 129.1, 131.0, 131.7, 133.2, 133.3, 135.5, 142.3, 148.9, 157.6, 207.8; MS (m/z, \%): $546.1\left([\mathrm{M}+\mathrm{H}]^{+}, 100\right), 568.2\left([\mathrm{M}+\mathrm{Na}]^{+}, 5\right), 213.2(\mathrm{~A}, 71)$; HR MS: formula: $\mathrm{C}_{29} \mathrm{H}_{24} \mathrm{Cl}_{2} \mathrm{~F}_{3} \mathrm{NNaO}_{2}$, cald: 568.1028 , found: 568.1025 .

(1e) 1-(3-Fluorophenyl)-5-(6-methoxynaphthalen-2-yl)-1-(4(trifluoromethyl)phenylamino)pentan-3-one

$(R=3-F)$ m.p. $140-143^{\circ} \mathrm{C}^{\circ 1} \mathrm{H}$ NMR (300 MHz, DMSO-d $\left.)_{6}\right): \delta 2.73-2.78$ (m, $\left.1 \mathrm{H},{ }^{*} \mathrm{CHCH}_{2}\right), 2.80-2.87\left(\mathrm{~m}, 4 \mathrm{H}, \mathrm{CH}_{2} \mathrm{CH}_{2}\right), 2.99(\mathrm{dd}, 1 \mathrm{H}, J=9.3,16.4 \mathrm{~Hz}$, $\left.{ }^{*} \mathrm{CHCH}_{2}\right), 3.85\left(\mathrm{~s}, 3 \mathrm{H}, \mathrm{OCH}_{3}\right), 4.72-4.77\left(\mathrm{~m}, 1 \mathrm{H},{ }^{*} \mathrm{CH}\right), 6.48(\mathrm{~d}, 2 \mathrm{H}, J=8.6$ $\left.\mathrm{Hz}, \mathrm{Ar}^{3}-\mathrm{H}\right), 6.90\left(\mathrm{~s}, 1 \mathrm{H}, \mathrm{Ar}^{2}-\mathrm{H}\right), 7.08-7.12\left(\mathrm{~m}, 3 \mathrm{H}, \mathrm{Ar}^{1}-\mathrm{H}\right.$ and $\left.2 \mathrm{Ar}^{2}-\mathrm{H}\right), 7.15(\mathrm{~d}$, $\left.1 \mathrm{H}, J=8.7 \mathrm{~Hz}, \mathrm{Ar}^{1}-\mathrm{H}\right), 7.19$ (d, $\left.1 \mathrm{H}, J=8.6 \mathrm{~Hz}, \mathrm{Ar}^{1}-\mathrm{H}\right), 7.30(\mathrm{~d}, 2 \mathrm{H}, J=8.6$ $\left.\mathrm{Hz}, \mathrm{Ar}^{3}-\mathrm{H}\right), 7.34-7.36\left(\mathrm{~m}, 1 \mathrm{H}, \mathrm{Ar}^{2}-\mathrm{H}\right), 7.45\left(\mathrm{~s}, 1 \mathrm{H}, \mathrm{Ar}^{1}-\mathrm{H}\right), 7.59-7.61(\mathrm{~m}, 2 \mathrm{H}$, $\left.\mathrm{Ar}^{1}-\mathrm{H}\right) ;{ }^{13} \mathrm{C}$ NMR $(75 \mathrm{MHz}$, DMSO-d $): \delta 29.9,45.2,46.8,54.2,55.8,105.7$, 113.0(2C), 113.5, 118.3, 119.1, 125.7(2C), 126.0, 126.6, 127.0, 127.6, 127.9, $128.0,128.1,128.9,129.1,133.2,135.7,143.0,149.0,157.5,162.6,207.9 ; \mathrm{MS}$ $(\mathrm{m} / \mathrm{z}, \%): 495.1\left([\mathrm{M}+\mathrm{H}]^{+}, 100\right), 518.1\left([\mathrm{M}+\mathrm{Na}]^{+}, 20\right), 213.2(\mathrm{~A}, 22)$. HR MS: formula: $\mathrm{C}_{29} \mathrm{H}_{25} \mathrm{~F}_{4} \mathrm{NNaO}_{2}$, cald: 518.1719 , found: 518.1728 .

(1f) 1-(4-Chlorophenyl)-5-(6-methoxynaphthalen-2-yl)-1-(4(trifluoromethyl)phenylamino)pentan-3-one $(R=4-\mathrm{Cl})$ m.p. $146-148^{\circ} \mathrm{C}{ }^{\circ} \mathrm{IR}$ $(\mathrm{KBr}): v 3309\left(v_{\mathrm{NH}}\right), 1716\left(v_{\mathrm{C}=\mathrm{O}}\right), 1614\left(v_{\mathrm{C}=\mathrm{C}}\right) ;{ }^{1} \mathrm{H}$ NMR $\left(300 \mathrm{MHz}, \mathrm{DMSO}-\mathrm{d}_{6}\right)$ : $\delta 2.72\left(\mathrm{dd}, 2 \mathrm{H}, J=7.9,17.6 \mathrm{~Hz},{ }^{*} \mathrm{CHCH}_{2}\right), 2.87\left(\mathrm{~d}, 2 \mathrm{H}, J=5.7 \mathrm{~Hz}, \mathrm{CH}_{2}\right)$, $2.96\left(\mathrm{t}, 2 \mathrm{H}, J=7.1 \mathrm{~Hz}, \mathrm{CH}_{2}\right), 3.91\left(\mathrm{~s}, 3 \mathrm{H}, \mathrm{OCH}_{3}\right), 4.72-4.80\left(\mathrm{~m}, 1 \mathrm{H},{ }^{*} \mathrm{CH}\right)$, $6.43\left(\mathrm{~d}, 2 \mathrm{H}, J=8.1 \mathrm{~Hz}, \mathrm{Ar}^{3}-\mathrm{H}\right), 7.10\left(\mathrm{~d}, 2 \mathrm{H}, J=5.0 \mathrm{~Hz}, \mathrm{Ar}^{2}-\mathrm{H}\right), 7.14(\mathrm{~d}, 1 \mathrm{H}$, $\left.J=2.4 \mathrm{~Hz}, \mathrm{Ar}^{1}-\mathrm{H}\right), 7.16\left(\mathrm{~d}, 1 \mathrm{H}, J=1.5 \mathrm{~Hz}, \mathrm{Ar}^{1}-\mathrm{H}\right), 7.18-7.30\left(\mathrm{~m}, 5 \mathrm{H}, \mathrm{Ar}^{1}-\mathrm{H}\right.$, $2 \mathrm{Ar}^{2}-\mathrm{H}$ and $\left.2 \mathrm{Ar}^{3}-\mathrm{H}\right), 7.45\left(\mathrm{~s}, 1 \mathrm{H}, \mathrm{Ar}^{1}-\mathrm{H}\right), 7.61\left(\mathrm{~d}, 2 \mathrm{H}, J=8.1 \mathrm{~Hz}, \mathrm{Ar}^{1}-\mathrm{H}\right) ;{ }^{13} \mathrm{C}$ NMR (75 MHz, DMSO-d ): $\delta 29.9,45.2,49.9,53.3,55.4,105.7,113.5(2 \mathrm{C})$, $118.9,119.2,123.7(2 \mathrm{C}), 126.2,126.6,126.8,127.6,127.9,128.0(2 \mathrm{C}), 128.1$, $128.9,129.1,133.2,134.9,135.7,143.0,149.0,157.5,207.9 ; \mathrm{MS}(\mathrm{m} / \mathrm{z}, \%)$ : $512.2\left([\mathrm{M}+\mathrm{H}]^{+}, 93\right), 534.1\left([\mathrm{M}+\mathrm{Na}]^{+}, 10\right), 213.2(\mathrm{~A}, 100)$; HR MS: formula: $\mathrm{C}_{29} \mathrm{H}_{25} \mathrm{ClF}_{3} \mathrm{NNaO}_{2}$, cald: 534.1418 , found: 534.1398 .

(1g) 1-(3-Chlorophenyl)-5-(6-methoxynaphthalen-2-yl)-1-(4(trifluoromethyl)phenylamino)pentan-3-one $(R=3-\mathrm{Cl})$ m.p. $176-178^{\circ} \mathrm{C} \mathrm{IR}$ $(\mathrm{KBr}): v 3349\left(v_{\mathrm{HH}}\right), 1703\left(v_{\mathrm{C}-\mathrm{O}}\right), 1612\left(\mathrm{v}_{\mathrm{C}-\mathrm{C}}\right) ;{ }^{1} \mathrm{H}$ NMR $(300 \mathrm{MHz}$, DMSO-d $\mathrm{c})$ : $\delta$ 2.74-2.79 (m, $\left.2 \mathrm{H},{ }^{*} \mathrm{CHCH}_{2}\right), 2.84\left(\mathrm{~d}, 2 \mathrm{H}, J=6.2 \mathrm{~Hz}, \mathrm{CH}_{2}\right), 2.95-3.02(\mathrm{~m}, 2 \mathrm{H}$, $\left.\mathrm{CH}_{2}\right), 3.91\left(\mathrm{~s}, 3 \mathrm{H}, \mathrm{OCH}_{3}\right), 4.76\left(\mathrm{t}, 1 \mathrm{H}, J=6.1 \mathrm{~Hz},{ }^{*} \mathrm{CH}\right), 6.45(\mathrm{~d}, 2 \mathrm{H}, J=8.4$
$\left.\mathrm{Hz}, \mathrm{Ar}^{3}-\mathrm{H}\right), 7.09$ (d, 1H, $\left.J=3.9 \mathrm{~Hz}, \mathrm{Ar}^{1}-\mathrm{H}\right), 7.14\left(\mathrm{~d}, 2 \mathrm{H}, J=2.0 \mathrm{~Hz}, \mathrm{Ar}^{1}-\mathrm{H}\right)$ $7.17\left(\mathrm{~d}, 1 \mathrm{H}, J=2.6 \mathrm{~Hz}, \mathrm{Ar}^{2}-\mathrm{H}\right), 7.20-7.23\left(\mathrm{~m}, 2 \mathrm{H}, \mathrm{Ar}^{2}-\mathrm{H}\right), 7.27-7.32(\mathrm{~m}, 3 \mathrm{H}$ $1 \mathrm{Ar}^{2}-\mathrm{H}$ and $\left.\mathrm{Ar}^{3}-\mathrm{H}\right), 7.47\left(\mathrm{~s}, 1 \mathrm{H}, \mathrm{Ar}^{1}-\mathrm{H}\right), 7.62\left(\mathrm{~d}, 2 \mathrm{H}, J=8.6 \mathrm{~Hz}, \mathrm{Ar}^{1}-\mathrm{H}\right) ;{ }^{13} \mathrm{C}$ NMR (75 MHz, DMSO-d ): $\delta$ 29.6, 45.3, 50.1, 53.8, 55.4, 105.8, 113.1(2C), $119.0,119.1,124.5(2 \mathrm{C}), 126.3,126.4,126.5,126.6,127.2,127.4,128.0,129.0$, $129.1,130.3,133.3,135.0,135.5,143.9,148.9,157.5,207.9 ; \mathrm{MS}(\mathrm{m} / \mathrm{z}, \%)$ : $512.2\left([\mathrm{M}+\mathrm{H}]^{+}, 100\right), 534.2\left([\mathrm{M}+\mathrm{Na}]^{+}, 5\right), 213.2(\mathrm{~A}, 32)$; HR MS: formula: $\mathrm{C}_{29} \mathrm{H}_{25} \mathrm{ClF}_{3} \mathrm{NNaO}_{2}$, cald: 534.1418 , found: 534.1403 .

(1i) 1-(3-Hydroxyphenyl)-5-(6-methoxynaphthalen-2-yl)-1-(4(trifluoromethyl)phenylamino)pentan-3-one $(R=3-\mathrm{OH}) \quad$ m.p. $\quad 82-84^{\circ} \mathrm{C}^{\circ} \mathrm{H}$ NMR (300 MHz, DMSO-d ) : $\delta 2.76\left(\mathrm{dd}, 1 \mathrm{H}, J=4.3,16.5 \mathrm{~Hz},{ }^{*} \mathrm{CHCH}_{2}\right), 2.80-$ $2.88\left(\mathrm{~m}, 4 \mathrm{H}, \mathrm{CH}_{2} \mathrm{CH}_{2}\right), 2.96\left(\mathrm{dd}, 1 \mathrm{H}, J=9.4,16.4 \mathrm{~Hz},{ }^{*} \mathrm{CHCH}_{2}\right), 3.85(\mathrm{~s}$, $\left.3 \mathrm{H}, \mathrm{OCH}_{3}\right), 4.80-4.84\left(\mathrm{~m}, 1 \mathrm{H},{ }^{*} \mathrm{CH}\right), 6.59-6.62\left(\mathrm{~m}, 3 \mathrm{H}, 1 \mathrm{Ar}^{2}-\mathrm{H}\right.$ and $\left.2 \mathrm{Ar}^{3}-\mathrm{H}\right)$, 6.78-6.81 (m, 2H, $\mathrm{Ar}^{1}-\mathrm{H}$ and $\left.\mathrm{Ar}^{2}-\mathrm{H}\right), 6.87(\mathrm{~d}, 1 \mathrm{H}, J=7.4 \mathrm{~Hz}, \mathrm{NH}), 7.06-7.12$ $\left(\mathrm{m}, 2 \mathrm{H}, \mathrm{Ar}^{1}-\mathrm{H}\right), 7.25-7.32\left(\mathrm{~m}, 4 \mathrm{H}, 2 \mathrm{Ar}^{2}-\mathrm{H}\right.$ and $\left.2 \mathrm{Ar}^{3}-\mathrm{H}\right), 7.56\left(\mathrm{~s}, 1 \mathrm{H}, \mathrm{Ar}^{1}-\mathrm{H}\right)$, $7.65-7.71\left(\mathrm{~m}, 2 \mathrm{H}, \mathrm{Ar}^{1}-\mathrm{H}\right), 9.35(\mathrm{~s}, 1 \mathrm{H}, \mathrm{OH}) ;{ }^{13} \mathrm{C}$ NMR $\left(75 \mathrm{MHz}, \mathrm{DMSO}-\mathrm{d}_{6}\right)$ : $\delta 28.7,43.6,50.2,52.3,55.1,105.7,112.6,113.0(2 \mathrm{C}), 113.3,117.0,118.5$, $119.7,125.8(2 \mathrm{C}), 126.1,127.6,128.5,128.7,129.5,132.7,133.6,136.2$, 144.6, 148.7, 150.8, 156.8, 163.5, 207.3; MS (m/z, \%): $494.1\left([\mathrm{M}+\mathrm{H}]^{+}, 100\right)$, $516.1\left([\mathrm{M}+\mathrm{Na}]^{+}, 5\right), 213.2(\mathrm{~A}, 42)$; HR MS: formula: $\mathrm{C}_{29} \mathrm{H}_{26} \mathrm{~F}_{3} \mathrm{~N} \mathrm{NaO}$, cald: 516.1762 , found: 568.1755 .

(1j)5-(6-Methoxynaphthalen-2-yl)-1-(3-methoxyphenyl)-1-(4(trifluoromethyl)phenylamino)pentan-3-one $\left(R=3-\mathrm{OCH}_{3}\right)$ m.p. $130-132^{\circ} \mathrm{C}^{\circ 1} \mathrm{H}$ NMR (300 MHz, DMSO-d ) : $\delta 2.80\left(\mathrm{dd}, 1 \mathrm{H}, J=4.3,16.4 \mathrm{~Hz},{ }^{*} \mathrm{CHCH}_{2}\right), 2.86-$ $2.92\left(\mathrm{~m}, 4 \mathrm{H}, \mathrm{CH}_{2} \mathrm{CH}_{2}\right), 3.01\left(\mathrm{dd}, 1 \mathrm{H}, J=9.4,16.4 \mathrm{~Hz},{ }^{*} \mathrm{CHCH}_{2}\right), 3.71(\mathrm{~s}$, $\left.3 \mathrm{H}, \mathrm{Ar}^{2}-\mathrm{OCH}_{3}\right), 3.85\left(\mathrm{~s}, 3 \mathrm{H}, \mathrm{Ar}^{1}-\mathrm{OCH}_{3}\right), 4.88-4.93\left(\mathrm{~m}, 1 \mathrm{H},{ }^{*} \mathrm{CH}\right), 6.63(\mathrm{~d}$, $\left.2 \mathrm{H}, J=8.4 \mathrm{~Hz}, \mathrm{Ar}^{3}-\mathrm{H}\right), 6.77$ (d, $\left.1 \mathrm{H}, J=7.2 \mathrm{~Hz}, \mathrm{Ar}^{2}-\mathrm{H}\right), 6.88-6.97(\mathrm{~m}, 3 \mathrm{H}$, $\mathrm{NH}, \mathrm{Ar}^{2}-\mathrm{H}$ nd $\left.\mathrm{Ar}^{1}-\mathrm{H}\right), 7.09-7.12\left(\mathrm{~m}, 1 \mathrm{H}, \mathrm{Ar}^{1}-\mathrm{H}\right), 7.21-7.32\left(\mathrm{~m}, 5 \mathrm{H}, \mathrm{Ar}^{1}-\mathrm{H}\right.$, $2 \mathrm{Ar}^{2}-\mathrm{H}$ and $\left.2 \mathrm{Ar}^{3}-\mathrm{H}\right), 7.56\left(\mathrm{~s}, 1 \mathrm{H}, \mathrm{Ar}^{1}-\mathrm{H}\right), 7.65-7.71\left(\mathrm{~m}, 2 \mathrm{H}, \mathrm{Ar}^{1}-\mathrm{H}\right) ;{ }^{13} \mathrm{C} \mathrm{NMR}$ $(75 \mathrm{MHz}$, DMSO-d $): \delta 28.7,43.5,50.2,52.3,54.9,55.1,105.7,112.0,112.3$, $112.7(2 \mathrm{C}), 118.4,118.5,125.8(2 \mathrm{C}), 126.1,127.6,128.5,128.7,129.5,132.7$, 136.2, 144.8, 148.7, 150.7, 156.8, 159.4, 207.0; MS (m/z, \%): $508.1\left([\mathrm{M}+\mathrm{H}]^{+}\right.$, 100), $530.1\left([\mathrm{M}+\mathrm{Na}]^{+}, 5\right), 213.2(\mathrm{~A}, 42)$; HR MS: formula: $\mathrm{C}_{30} \mathrm{H}_{28} \mathrm{~F}_{3} \mathrm{~N} \mathrm{NaO}$, cald: 530.1919 , found: 530.1903

(1k)1-(4-Bromophenyl)-5-(6-methoxynaphthalen-2-yl)-1-(4(trifluoromethyl)phenylamino)pentan-3-one $(R=4-B r)$ m.p. $173-175^{\circ} \mathrm{C}^{\circ 1} \mathrm{H}$ NMR (300 MHz, DMSO-d $): \delta 2.80\left(\mathrm{dd}, 1 \mathrm{H}, J=5.0,16.3 \mathrm{~Hz}, * \mathrm{CHCH}_{2}\right), 2.87-$ $2.95\left(\mathrm{~m}, 4 \mathrm{H}, \mathrm{CH}_{2} \mathrm{CH}_{2}\right), 3.02\left(\mathrm{dd}, 1 \mathrm{H}, J=9.1,16.3 \mathrm{~Hz},{ }^{*} \mathrm{CHCH}_{2}\right), 3.85$ (s, $\left.3 \mathrm{H}, \mathrm{OCH}_{3}\right), 4.85-4.91(\mathrm{~m}, 1 \mathrm{H}, * \mathrm{CH}), 6.59\left(\mathrm{~d}, 2 \mathrm{H}, J=8.6 \mathrm{~Hz}, \mathrm{Ar}^{3}-\mathrm{H}\right), 7.09$ $\left(\mathrm{d}, 1 \mathrm{H}, J=2.6 \mathrm{~Hz}, \mathrm{Ar}^{1}-\mathrm{H}\right), 7.14\left(\mathrm{~s}, 1 \mathrm{H}, \mathrm{Ar}^{1}-\mathrm{H}\right), 7.18-7.22\left(\mathrm{~m}, 3 \mathrm{H}, \mathrm{Ar}^{1}-\mathrm{H}\right.$ and $\left.2 \mathrm{Ar}^{2}-\mathrm{H}\right), 7.30\left(\mathrm{~d}, 2 \mathrm{H}, J=8.5 \mathrm{~Hz}, \mathrm{Ar}^{3}-\mathrm{H}\right), 7.50\left(\mathrm{~s}, 1 \mathrm{H}, \mathrm{Ar}^{1}-\mathrm{H}\right), 7.59-7.62(\mathrm{~m}$, $\left.2 \mathrm{H}, \mathrm{Ar}^{1}-\mathrm{H}\right), 7.83\left(\mathrm{~d}, 2 \mathrm{H}, J=8.5 \mathrm{~Hz}, \mathrm{Ar}^{2}-\mathrm{H}\right) ;{ }^{13} \mathrm{C}$ NMR $(75 \mathrm{MHz}$, DMSO-d $): \delta$ $29.2,45.8,49.6,53.0,55.6,105.7,113.5(2 \mathrm{C}), 118.5,119.4,125.6(2 \mathrm{C}), 126.2$, $126.6,126.8,127.6,127.8,128.3,128.5,128.9,129.4,133.2,134.9,135.7$, 143.0, 149.0, 150.8, 157.5, 208.1; MS (m/z, \%):555.1 ([M+H] $\left.{ }^{+}, 100\right), 578.1$ $\left([\mathrm{M}+\mathrm{Na}]^{+}, 10\right), 213.2(\mathrm{~A}, 23)$; HR MS: formula: $\mathrm{C}_{29} \mathrm{H}_{25} \mathrm{BrF}_{3} \mathrm{NNaO}_{2}$, cald: 578.0916 , found: 578.0911

(11)5-(6-Methoxynaphthalen-2-yl)-1-phenyl-1-(4-(trifluoromethyl) phenylamino)pentan-3-one $(R=H)$ m.p. $167-169^{\circ} \mathrm{C}^{\circ} \mathrm{IR}(\mathrm{KBr}): \vee 3409\left(v_{\mathrm{vH}}\right)$, $1718\left(v_{\mathrm{C}=\mathrm{O}}\right), 1614\left(v_{\mathrm{C}=\mathrm{C}}\right) ;{ }^{1} \mathrm{H}$ NMR $\left(300 \mathrm{MHz}, \mathrm{DMSO}-\mathrm{d}_{6}\right): \delta 2.71(\mathrm{dd}, 2 \mathrm{H}, J$ $\left.=7.9,17.6 \mathrm{~Hz},{ }^{*} \mathrm{CHCH}_{2}\right), 2.88\left(\mathrm{~d}, 2 \mathrm{H}, J=6.2 \mathrm{~Hz}, \mathrm{CH}_{2}\right), 2.92-2.96(\mathrm{~m}, 2 \mathrm{H}$, $\left.\mathrm{CH}_{2}\right), 3.89\left(\mathrm{~s}, 3 \mathrm{H}, \mathrm{OCH}_{3}\right), 4.76-4.82\left(\mathrm{~m}, 1 \mathrm{H},{ }^{*} \mathrm{CH}\right), 6.46(\mathrm{~d}, 2 \mathrm{H}, J=8.6 \mathrm{~Hz}$, $\left.\mathrm{Ar}^{3}-\mathrm{H}\right), 7.07\left(\mathrm{~d}, 1 \mathrm{H}, J=2.1 \mathrm{~Hz}, \mathrm{Ar}^{1}-\mathrm{H}\right), 7.09-7.12\left(\mathrm{~m}, 1 \mathrm{H}, \mathrm{Ar}^{1}-\mathrm{H}\right), 7.14-7.17$ $\left(\mathrm{m}, 1 \mathrm{H}, \mathrm{Ar}^{1}-\mathrm{H}\right), 7.24\left(\mathrm{~d}, 2 \mathrm{H}, J=7.5 \mathrm{~Hz}, \mathrm{Ar}^{2}-\mathrm{H}\right), 7.24-7.27$ (m, $\left.3 \mathrm{H}, \mathrm{Ar}^{2}-\mathrm{H}\right)$, $7.28\left(\mathrm{~d}, 2 \mathrm{H}, J=7.9 \mathrm{~Hz}, \mathrm{Ar}^{3}-\mathrm{H}\right), 7.45\left(\mathrm{~s}, 1 \mathrm{H}, \mathrm{Ar}^{1}-\mathrm{H}\right), 7.59(\mathrm{~d}, 2 \mathrm{H}, J=8.6 \mathrm{~Hz}$, $\left.\mathrm{Ar}^{1}-\mathrm{H}\right) ;{ }^{13} \mathrm{C}$ NMR $(75 \mathrm{MHz}$, DMSO-d $): \delta 29.5,45.4,50.3,54.1,55.4,105.7$, $112.9(2 \mathrm{C}), 119.0,119.6,123.2,125.8(2 \mathrm{C}), 126.2,126.4,126.5,126.6,127.1$, $127.5,127.8,128.9,129.1,133.2,135.8,141.6,149.3,157.5,208.5 ; \mathrm{MS}(\mathrm{m} / \mathrm{z}$, $\%): 478.2\left([\mathrm{M}+\mathrm{H}]^{+}, 100\right), 500.2\left([\mathrm{M}+\mathrm{Na}]^{+}, 9\right), 213.2(\mathrm{~A}, 78)$. HR MS: formula: $\mathrm{C}_{20} \mathrm{H}_{2} \mathrm{~F}_{3} \mathrm{NNaO}$, cald: 500.1812 , found: 500.1802 .

(1m)5-(6-Methoxynaphthalen-2-yl)-1-m-tolyl-1-(4-(trifluoromethyl) phenylamino)pentan-3-one $\left(R=3-\mathrm{CH}_{3}\right)$ m.p. $177-179^{\circ} \mathrm{C}^{\circ} \mathrm{IR}(\mathrm{KBr}): v 3347$ $\left(v_{\mathrm{NH}}\right), 1702\left(v_{\mathrm{C}=\mathrm{O}}\right), 1610\left(v_{\mathrm{C}=\mathrm{C}}\right) ;{ }^{1} \mathrm{H}$ NMR $\left(300 \mathrm{MHz}, \mathrm{DMSO}-\mathrm{d}_{6}\right): \delta 2.31(\mathrm{~s}, 3 \mathrm{H}$, $\left.\mathrm{CH}_{3}\right), 2.74\left(\mathrm{dd}, 2 \mathrm{H}, J=7.9,17.6 \mathrm{~Hz},{ }^{*} \mathrm{CHCH}_{2}\right), 2.88\left(\mathrm{~d}, 2 \mathrm{H}, J=6.1 \mathrm{~Hz}, \mathrm{CH}_{2}\right)$, $2.96\left(\mathrm{t}, 2 \mathrm{H}, J=7.1 \mathrm{~Hz}, \mathrm{CH}_{2}\right), 3.91\left(\mathrm{~s}, 3 \mathrm{H}, \mathrm{OCH}_{3}\right), 4.72-4.797\left(\mathrm{~m}, 1 \mathrm{H},{ }^{*} \mathrm{CH}\right)$, $6.47\left(\mathrm{~d}, 2 \mathrm{H}, J=8.4 \mathrm{~Hz}, \mathrm{Ar}^{3}-\mathrm{H}\right), 7.05-7.10\left(\mathrm{~m}, 4 \mathrm{H}, 3 \mathrm{Ar}^{2}-\mathrm{H}\right.$ and $\left.1 \mathrm{Ar}^{1}-\mathrm{H}\right), 7.13$ (s, $\left.1 \mathrm{H}, \mathrm{Ar}^{2}-\mathrm{H}\right), 7.17-7.20\left(\mathrm{~m}, 2 \mathrm{H}, \mathrm{Ar}^{1}-\mathrm{H}\right), 7.29\left(\mathrm{~d}, 2 \mathrm{H}, J=8.5 \mathrm{~Hz}, \mathrm{Ar}^{3}-\mathrm{H}\right), 7.46$ (s, $\left.1 \mathrm{H}, \mathrm{Ar}^{1}-\mathrm{H}\right), 7.61\left(\mathrm{~d}, 2 \mathrm{H}, J=8.8 \mathrm{~Hz}, \mathrm{Ar}^{1}-\mathrm{H}\right) ;{ }^{13} \mathrm{C}$ NMR $\left(75 \mathrm{MHz}\right.$, DMSO-d $\mathrm{d}_{6}$ : $\delta 24.3,29.3,45.8,50.1,53.2,55.4,105.7,113.5(2 \mathrm{C}), 119.1,119.4,125.1(2 \mathrm{C})$, $126.1,126.5,126.8,127.6,127.9,128.0,128.3,128.8,128.8,129.1,132.1$, 134.8, 135.8, 142.1, 148.4, 157.5, 207.5; MS (m/z, \%): $492.2\left([\mathrm{M}+\mathrm{H}]^{+}, 100\right)$, 514.2 ([M+ Na $\left.]^{+}, 12\right)$, $213.2(\mathrm{~A}, 69)$; HR MS: formula: $\mathrm{C}_{30} \mathrm{H}_{28} \mathrm{~F}_{3} \mathrm{NNaO}_{2}$, cald: 514.1964 , found: 514.1969 . 
(1n)5-(6-Methoxynaphthalen-2-yl)-1-p-tolyl-1-(4-(trifluoromethyl) phenylamino)pentan-3-one $\left(R=4-\mathrm{CH}_{3}\right)$ m.p. $116-117^{\circ} \mathrm{C}$; ${ }^{1} \mathrm{H} \mathrm{NMR}(300 \mathrm{MHz}$, DMSO-d $): \delta 2.23\left(\mathrm{~s}, 3 \mathrm{H}, \mathrm{CH}_{3}\right), 2.77\left(\mathrm{dd}, 1 \mathrm{H}, J=4.7,16.3 \mathrm{~Hz},{ }^{*} \mathrm{CHCH}_{2}\right)$, 2.83-2.90 (m, 4H, $\left.\mathrm{CH}_{2} \mathrm{CH}_{2}\right), 3.00\left(\mathrm{~d}, 1 \mathrm{H}, J=9.0,16.3 \mathrm{~Hz},{ }^{*} \mathrm{CHCH}_{2}\right), 3.85(\mathrm{~s}$, $\left.3 \mathrm{H}, \mathrm{CH}_{3}\right), 4.84-4.93\left(\mathrm{~m}, 1 \mathrm{H},{ }^{*} \mathrm{CH}\right), 6.61\left(\mathrm{~d}, 2 \mathrm{H}, J=8.3 \mathrm{~Hz}, \mathrm{Ar}^{3}-\mathrm{H}\right), 6.88(\mathrm{~d}$ $1 \mathrm{H}, J=7.7 \mathrm{~Hz}, \mathrm{NH}), 7.07-7.12\left(\mathrm{~m}, 3 \mathrm{H}, 2 \mathrm{Ar}^{2}-\mathrm{H}\right.$ and $\left.\mathrm{Ar}^{1}-\mathrm{H}\right), 7.24-7.37(\mathrm{~m}, 6 \mathrm{H}$, $2 \mathrm{Ar}^{2}-\mathrm{H}, 2 \mathrm{Ar}^{3}-\mathrm{H}$ and $\left.2 \mathrm{Ar}^{1}-\mathrm{H}\right), 7.55\left(\mathrm{~s}, 1 \mathrm{H}, \mathrm{Ar}^{1}-\mathrm{H}\right), 7.65-7.74\left(\mathrm{~m}, 2 \mathrm{H}, \mathrm{Ar}^{1}-\mathrm{H}\right)$; ${ }^{13} \mathrm{C}$ NMR (75 MHz, DMSO-d $)$ : $\delta 20.7,28.7,43.59,50.30,52.14,55.8,105.7$, 112.3(2C), 115.8, 118.5, 123.5(2C), 125.8(2C), 126.1, 127.1, 127.7, 128.6, $128.8(2 \mathrm{C}), 129.0,132.8,136.0,136.2,140.0,150.8,156.8,207.2 ; \mathrm{MS}(\mathrm{m} / \mathrm{z}$, \%): $492.1\left([\mathrm{M}+\mathrm{H}]^{+}, 50\right), 514.0\left([\mathrm{M}+\mathrm{Na}]^{+}, 25\right), 213.2(\mathrm{~A}, 76)$. HR MS: formula: $\mathrm{C}_{30} \mathrm{H}_{28} \mathrm{~F}_{3} \mathrm{~N} \mathrm{NaO}$, cald: 514.1969 , found: 514.1952.

(1o) 5-(6-Methoxynaphthalen-2-yl)-1-(4-methoxyphenyl)-1-(4(trifluoromethyl)phenylamino)pentan-3-one $\left(R=4-O C H_{3}\right)$ m.p. $171-173^{\circ} \mathrm{C}^{\circ} \mathrm{IR}$ $(\mathrm{KBr}): v 3305\left(v_{\mathrm{N}}\right), 1718\left(\mathrm{v}_{\mathrm{C}-0}\right), 1613\left(\mathrm{v}_{\mathrm{CC}}\right)$; ${ }^{1} \mathrm{H}$ NMR $(300 \mathrm{MHz}, \mathrm{DMSO}-\mathrm{d})$ : $\delta 2.71-2.75\left(\mathrm{t}, 2 \mathrm{H}, J=7.3 \mathrm{~Hz}, \mathrm{CH}_{2}\right), 2.87\left(\mathrm{~d}, 2 \mathrm{H}, J=6.1 \mathrm{~Hz}, \mathrm{CH}_{2}\right), 2.95(\mathrm{t}, 2 \mathrm{H}$, $\left.J=7.3 \mathrm{~Hz}, \mathrm{CH}_{2}\right), 3.76\left(\mathrm{~s}, 3 \mathrm{H}, \mathrm{Ar}^{2}-\mathrm{OCH}_{3}\right), 3.91\left(\mathrm{~s}, 3 \mathrm{H}, \mathrm{Ar}^{1}-\mathrm{OCH}_{3}\right), 4.73-4.78$ $\left(\mathrm{m}, 1 \mathrm{H},{ }^{*} \mathrm{CH}\right), 6.48\left(\mathrm{~d}, 2 \mathrm{H}, J=8.4 \mathrm{~Hz}, \mathrm{Ar}^{3}-\mathrm{H}\right), 6.82\left(\mathrm{~d}, 2 \mathrm{H}, J=8.6 \mathrm{~Hz}, \mathrm{Ar}^{2}-\mathrm{H}\right)$, $7.09\left(\mathrm{~s}, 1 \mathrm{H}, \mathrm{Ar}^{1}-\mathrm{H}\right), 7.10-7.13\left(\mathrm{~m}, 1 \mathrm{H}, \mathrm{Ar}^{1}-\mathrm{H}\right), 7.15-7.19\left(\mathrm{~m}, 3 \mathrm{H}, 1 \mathrm{Ar}^{1}-\mathrm{H}\right.$ and $\left.2 \mathrm{Ar}^{2}-\mathrm{H}\right), 7.29$ (d, $\left.2 \mathrm{H}, J=8.5 \mathrm{~Hz}, \mathrm{Ar}^{3}-\mathrm{H}\right), 7.45\left(\mathrm{~s}, 1 \mathrm{H}, \mathrm{Ar}^{1}-\mathrm{H}\right), 7.62$ (d, $2 \mathrm{H}, J=$ $\left.8.5 \mathrm{~Hz}, \mathrm{Ar}^{1}-\mathrm{H}\right) ;{ }^{13} \mathrm{C}$ NMR (75 MHz, DMSO-d $)$ ): $\delta 29.5,45.4,49.3,50.3,53.6$, 55.4, 105.7, 112.9(2C), 114.4(2C), 118.9, 119.0, 126.4(2C), 126.5, 126.6(2C), 127.1, 127.2, 127.4, 127.5, 129.0, 133.2, 133.5, 135.8, 149.4, 157.5, 159.1, 208.7; MS (m/z, \%): $530.2\left([\mathrm{M}+\mathrm{Na}]^{+}, 16\right), 213.2$ (A, 100); HRMS: formula: $\mathrm{C}_{30} \mathrm{H}_{28} \mathrm{~F}_{3} \mathrm{NNaO}_{3}$, calcd: 530.1913 , found: 530.189

(1p) 1-(4-Butoxyphenyl)-5-(6-methoxynaphthalen-2-yl)-1-(4(trifluoromethyl)phenylamino)pentan-3-one $\left(R=4-\left(n-O C_{4} H_{0}\right)\right) \quad \mathrm{m} . \mathrm{p}$ $143-145^{\circ} \mathrm{C}^{\circ} \mathrm{H}$ NMR (300 MHz, DMSO-d $)$ : $\delta 0.91$ (t, $3 \mathrm{H}, J=7.3 \mathrm{~Hz}, \mathrm{CH}_{3}$ ), $1.38-1.44\left(\mathrm{~m}, 2 \mathrm{H}, \mathrm{CH}_{2} \mathrm{CH}_{3}\right), 1.62-1.67\left(\mathrm{~m}, 2 \mathrm{H}, \mathrm{CH}_{2} \mathrm{CH}_{2} \mathrm{CH}_{3}\right), 2.69(\mathrm{dd}, 1 \mathrm{H}, J=$ 8.0, $\left.17.3 \mathrm{~Hz},{ }^{*} \mathrm{CHCH}_{2}\right), 2.86-2.94\left(\mathrm{~m}, 4 \mathrm{H}, \mathrm{CH}_{2}\right), 2.98-3.02\left(\mathrm{~m}, 1 \mathrm{H},{ }^{*} \mathrm{CHCH}_{2}\right)$, $3.89\left(\mathrm{t}, 2 \mathrm{H}, J=6.3 \mathrm{~Hz}, \mathrm{OCH}_{2}\right), 4.77-4.83\left(\mathrm{~m}, 1 \mathrm{H},{ }^{*} \mathrm{CH}\right), 6.50(\mathrm{~d}, 2 \mathrm{H}, J=8.6$ $\left.\mathrm{Hz}, \mathrm{Ar}^{3}-\mathrm{H}\right), 6.89-6.94\left(\mathrm{~m}, 3 \mathrm{H}, 2 \mathrm{Ar}^{2}-\mathrm{H}\right.$ and $\left.\mathrm{NH}\right), 7.10\left(\mathrm{~s}, 1 \mathrm{H}, \mathrm{Ar}^{1}-\mathrm{H}\right), 7.12-7.15$ $\left(\mathrm{m}, 1 \mathrm{H}, \mathrm{Ar}^{1}-\mathrm{H}\right), 7.18-7.22\left(\mathrm{~m}, 3 \mathrm{H}, 1 \mathrm{Ar}^{1}-\mathrm{H}\right.$ and $\left.2 \mathrm{Ar}^{2}-\mathrm{H}\right), 7.30(\mathrm{~d}, 2 \mathrm{H}, J=8.5$ $\left.\mathrm{Hz}, \mathrm{Ar}^{3}-\mathrm{H}\right), 7.45$ (s, $\left.1 \mathrm{H}, \mathrm{Ar}^{1}-\mathrm{H}\right), 7.60-7.63\left(\mathrm{~m}, 2 \mathrm{H}, \mathrm{Ar}^{1}-\mathrm{H}\right) ;{ }^{13} \mathrm{C}$ NMR $(75 \mathrm{MHz}$, DMSO-d ): $\delta 14.5,19.9,29.9,31.6,45.2,46.8,54.2,55.8,68.2,105.7,113.8$, 118.6, 119.1, 126.0, 126.6, 127.2, 127.6, 127.9, 128.3, 128.6, 129.0, 129.8, $133.2,135.7,143.0,149.0,162.5,164.6,208.2 ; \mathrm{MS}(\mathrm{m} / \mathrm{z}, \%): 549.2\left([\mathrm{M}+\mathrm{H}]^{+}\right.$ 100), $572.2\left([\mathrm{M}+\mathrm{Na}]^{+}, 10\right), 213.2$ (A, 31). HR MS: formula: $\mathrm{C}_{33} \mathrm{H}_{34} \mathrm{~F}_{3} \mathrm{~N} \mathrm{NaO}{ }_{3}$, cald: 572.2388 , found: 572.2365 .

(1q) (Benzo [d] [1,3]dioxol-5-yl)-5-(6-methoxynaphthalen-2-yl)-1(4-(trifluoromethyl)phenylamino)-pentan -3-one $\left(\mathrm{R}=3,4-\mathrm{OCH}_{2} \mathrm{O}\right)$ m.p. $155-157^{\circ} \mathrm{C}^{\circ} \mathrm{IR}(\mathrm{KBr}): v 3340\left(v_{\mathrm{NH}}\right), 1708\left(v_{\mathrm{C}=\mathrm{O}}\right), 1611\left(v_{\mathrm{C}-\mathrm{C}}\right) ;{ }^{1} \mathrm{H}$ NMR $(300$ MHz, DMSO-d $\left.{ }_{6}\right): \delta 2.68\left(\mathrm{dd}, 2 \mathrm{H}, J=7.9,17.6 \mathrm{~Hz},{ }^{*} \mathrm{CHCH}_{2}\right), 2.85(\mathrm{~d}, 2 \mathrm{H}, J$ $\left.=6.2 \mathrm{~Hz}, \mathrm{CH}_{2}\right), 2.97\left(\mathrm{t}, 2 \mathrm{H}, J=7.1 \mathrm{~Hz}, \mathrm{CH}_{2}\right), 3.91\left(\mathrm{~s}, 3 \mathrm{H}, \mathrm{OCH}_{3}\right), 4.71-4.83$ $\left(\mathrm{m}, 1 \mathrm{H},{ }^{*} \mathrm{CH}\right), 5.91\left(\mathrm{~s}, 2 \mathrm{H}, \mathrm{OCH}_{2} \mathrm{O}\right), 6.47\left(\mathrm{~d}, 2 \mathrm{H}, J=8.3 \mathrm{~Hz}, \mathrm{Ar}^{3}-\mathrm{H}\right), 6.72(\mathrm{~d}$, $\left.2 \mathrm{H}, J=2.7 \mathrm{~Hz}, \mathrm{Ar}^{2}-\mathrm{H}\right), 6.76\left(\mathrm{~s}, 1 \mathrm{H}, \mathrm{Ar}^{2}-\mathrm{H}\right), 7.10\left(\mathrm{~s}, 1 \mathrm{H}, \mathrm{Ar}^{1}-\mathrm{H}\right), 7.11(\mathrm{~d}, 1 \mathrm{H}$, $\left.J=8.9 \mathrm{~Hz}, \mathrm{Ar}^{1}-\mathrm{H}\right), 7.20\left(\mathrm{~d}, 1 \mathrm{H}, J=8.2 \mathrm{~Hz}, \mathrm{Ar}^{1}-\mathrm{H}\right), 7.29(\mathrm{~d}, 2 \mathrm{H}, J=8.4 \mathrm{~Hz}$, $\left.\mathrm{Ar}^{3}-\mathrm{H}\right), 7.46\left(\mathrm{~s}, 1 \mathrm{H}, \mathrm{Ar}^{1}-\mathrm{H}\right), 7.62\left(\mathrm{~d}, 2 \mathrm{H}, J=8.5 \mathrm{~Hz}, \mathrm{Ar}^{1}-\mathrm{H}\right) ;{ }^{13} \mathrm{C}$ NMR $(75$ MHz, DMSO-d ${ }_{6}$ : $\delta$ 29.5, 45.4, 50.5, 54.0, 55.4, 101.3, 105.8, 106.6, 108.7, 113.0(2C), 119.08, 119.1, 119.5, 123.6, 126.4, 126.6, 127.0, 127.2, 127.5, $129.0,133.3,135.6,135.8,147.1,148.3,149.3,157.5,208.5 ; \mathrm{MS}(\mathrm{m} / \mathrm{z}, \%)$ : $544.2\left([\mathrm{M}+\mathrm{Na}]^{+}, 21\right), 213.3$ (A, 38); HR MS: formula: $\mathrm{C}_{30} \mathrm{H}_{26} \mathrm{~F}_{3} \mathrm{NNaO}_{4}$, cald: 544.1706 , found: 544.1682 .

(1r) 1-(4-Hydroxyphenyl)-5-(6-methoxynaphthalen-2-yl)-1-(4(trifluoromethyl)phenylamino)pentan-3-one $(R=4-\mathrm{OH})$ m.p. $165-167^{\circ} \mathrm{C}^{\mathrm{ol}} \mathrm{H}$ NMR (300 MHz, DMSO-d ) : $\delta 2.75\left(\mathrm{dd}, 1 \mathrm{H}, J=4.5,16.2 \mathrm{~Hz},{ }^{*} \mathrm{CHCH}_{2}\right), 2.79-$ $2.90\left(\mathrm{~m}, 4 \mathrm{H}, \mathrm{CH}_{2} \mathrm{CH}_{2}\right), 2.97\left(\mathrm{dd}, 1 \mathrm{H}, J=9.0,16.0 \mathrm{~Hz},{ }^{*} \mathrm{CHCH}_{2}\right), 3.85(3 \mathrm{H}, \mathrm{s}$, $\left.\mathrm{OCH}_{3}\right), 4.77-4.86\left(\mathrm{~m}, 1 \mathrm{H},{ }^{*} \mathrm{CH}\right), 6.61\left(\mathrm{~d}, 2 \mathrm{H}, J=8.3 \mathrm{~Hz}, \mathrm{Ar}^{3}-\mathrm{H}\right), 6.67(\mathrm{~d}, 2 \mathrm{H}, J$ $\left.=7.8 \mathrm{~Hz}, \mathrm{Ar}^{2}-\mathrm{H}\right), 6.82(\mathrm{~d}, 1 \mathrm{H}, J=7.5 \mathrm{~Hz}, \mathrm{NH}), 7.11\left(\mathrm{~d}, 1 \mathrm{H}, J=8.9 \mathrm{~Hz}, \mathrm{Ar}^{1}-\mathrm{H}\right)$, $7.17\left(\mathrm{~d}, 2 \mathrm{H}, J=8.0 \mathrm{~Hz}, \mathrm{Ar}^{2}-\mathrm{H}\right), 7.25-7.30\left(\mathrm{~m}, 4 \mathrm{H}, 2 \mathrm{Ar}^{3}-\mathrm{H}\right.$ and $\left.2 \mathrm{Ar}^{1}-\mathrm{H}\right), 7.54$ (s, $\left.1 \mathrm{H}, \mathrm{Ar}^{1}-\mathrm{H}\right), 7.65-7.71\left(\mathrm{~m}, 2 \mathrm{H}, \mathrm{Ar}^{1}-\mathrm{H}\right), 9.29(\mathrm{~s}, 1 \mathrm{H}, \mathrm{OH}) ;{ }^{13} \mathrm{C} \mathrm{NMR}(75 \mathrm{MHz}$, DMSO-d ): $\delta 29.7,44.5,51.4,52.8,56.0,106.6,113.1(2 \mathrm{C}), 116.1(2 \mathrm{C}), 119.4$ $125.6(2 \mathrm{C}), 126.8,127.0(2 \mathrm{C}), 127.6,128.4,128.6,129.4,129.5,129.7,133.7$, 134.0, 137.1, 151.7, 157.2, 157.7, 208.3; MS (m/z, \%): $494.1\left([\mathrm{M}+\mathrm{H}]^{+}, 100\right)$ $516.1\left([\mathrm{M}+\mathrm{Na}]^{+}, 20\right), 213.2(\mathrm{~A}, 42)$; HR MS: formula: $\mathrm{C}_{29} \mathrm{H}_{26} \mathrm{~F}_{3} \mathrm{~N} \mathrm{NaO}_{3}$, cald: 516.1762, found: 568.1748 .

\section{ACKNOWLEDGEMENT}

We appreciate for Mr. Ning Wang kindly assistance in NMR spectra measurements.

\section{REFERENCES}

[1] F. Akihiro, A. Tsuyoshi, S. Susumu, W. Kenji, Bioorg. Med. Chem. Lett. 20, 2095, (2010).

[2] V. Patil, K. Tilekar, M.Mu. Sonali, R. Mohan, C.S. Ramaa, Eur. J. Med. Chem. 45, 4539, (2010).

[3] J. Yang, S. Wei, D.-S. Wang, Y.-C. Wang, S.K. Kulp, C.-S. Chen, J. Med. Chem. 51, 2100, (2008).

[4] A. Arrault, S. Rocchi, F. Picard, P. Maurois, B. Pirotte, J. Vamecq, Biomed. Pharmacother. 63, 56, (2009).

[5] M.-M. Chao, H. Masao, D. Mohsen, L.-L. Wang, J. Med. Chem. 51, $6188,(2008)$.

[6] K. Kiraly, A.-M. Lambeir, J. Szalai, A. Szentirmay, W. Luyten, I. Barna, Z. Puskar, M. Kozsurek, A. Z. Ronai, Eur. J. Pharmacol. 650, 195, (2011).

[7] E. M. Migoya, J. L. Miller, M. Gutierrez, W. Zheng, A. O. JohnsonLevonas, Q. Liu, C. Z. Matthews, J. A. Wagner, K. M. Gottesdiener, Clin. Drug Invest. 30, 855, (2010).

[8] A. J. Scheen, G. Charpentier, C. J. Oestgren, A. Hellqvist, I. GauseNilsson, Diabetes Metabol Res. Rev. 26, 540, (2010).

[9] B. R. P. Kumar, M. J. Nanjan, Bioorg. Med. Chem. Lett. 20, 1953, (2010).

[10] M. Azend, B. Westermann, N. Risch, Angew. Chem. Int. Ed. 37, 1044, (1998).

[11] I. H. Hall, K. H. Lee, E. C. Mar, C. O. Starnes, T. G. Waddell, J. Med. Chem. 20, 333, (1977).

[12] A. A. Mohamed, S. Mohammad, Bioorg. Med. Chem. Lett. 17, 3314, (2007).

[13] L.-Y. Mou, Z.-Y. Lin, J. Liu, Q.-D. Zhang, L.-Y. Zhu, W.-J. Wang, Z.-G. Nie, Y. He, Acta. Pharm. Sin. 43, 917, (2008).

[14] C. Zhou, G. Wu, Y. Feng, Q. Li, H. Su, D. E. Mais, Y. Zhu, N. Li, Y. Deng, D. Yang, M.-W. Wang, Br. J. Pharm. 154, 440, (2008).

[15] A. R. Rote, S.R. Bhalerao, E-J. Chem. 7, 1463, (2010).

[16] BYH. R. Snyder, H. A. Korberg, J. R. Romig, J. Am. Chem. Soc. 61, 3556, (1939).

[17] M.-F. Liu, B.-L. Wang, W.-J. Lu, Chin. J. Org. Chem. 20, 738, (2000).

[18] B. R. Bhattarai, S. Shrestha, S.W. Ham, J. Bioorg. Med. Chem. 15, 535, (2007).

[19] J. K. D. Ufa, G.W. Reinwhold, US 4804675, (1989).

[20] X. M. Tang, L. Fan, H. X. Yu, Y. H. Liao, D. C. Yang, Chin. J. Org. Chem. 29, 595, (2009).

[21] (a) Z. Mohamed, B. Bouchaib, Tetrahedron Lett. 45, 4135, (2004); (b) J. J. Eisch, R. Sanchez, J. Org. Chem. 51, 1848, (1986); (c) W. T. Hua, F. Q. Ning, Chem. commun. 7, 27, (1991)

[22] Y.-Z. Ma, L.-N. Yin, X.-Y. Liu, Chin. J. Org. Chem. 16, 144, (2006).

[23] G. Zhao, M. Shi, J. Beijing. Normal Univ. Nat. Sci. Ed. 33, 221, (1997).

[24] N. G. Kozlov, L. I. Basalaeva, Russ. J. Gen. Chem. 74, 926, (2004).

[25] M. Kidwai, N. K. Bansal, A. Kumar, S. Mozumdar, Tetrahedron Lett. 50, 1355, (2009).

[26] (a) M. Periasamy, S. Suresh, S.S. Ganesan, Tetrahedron Lett. 46, 5521, (2005); (b) R. Wang, B.-G. Li, Tetrahedron Lett. 48, 2071, (2007); (c) X.-M. Chen, X.-S. Li, AS. C. Chan, Chin. Chem. Lett. 20, 407, (2009).

[27] (a) H. Wu, Y. Shen, L.-Y. Fan, Tetrahedron 63, 2404, (2007); (b) S. Suman, J. Trissa, SB. M. Halligudi, J. Mol. Catal. A. Chem. 24, 179, (2006); (c) M. Xia, Y.-.D. Lu, J. Fluor. Chem. 127, 1119, (2006).

[28] C.-T. Chang, B.-S. Liao, S.-T. Liu, Tetrahedron Lett. 47, 9257, (2006).

[29] H. Wu, X-M. Chen, Y. Wan, L. Ye, H.-Q. Xin, Tetrahedron Lett. 50, $1062,(2009)$.

[30] M. Wu, H.-W. Jing, T. Chang, Catal. Commun. 8, 2217, (2007). 